\title{
A New Generation of Vaccines in the Age of Immunotherapy
}

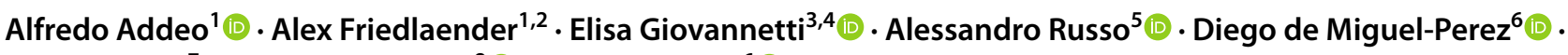 \\ Oscar Arrieta ${ }^{7} \cdot$ Andres F. Cardona $^{8}$ (1) Christian Rolfo ${ }^{6}$
}

Accepted: 24 April 2021 / Published online: 4 November 2021

(c) The Author(s), under exclusive licence to Springer Science+Business Media, LLC, part of Springer Nature 2021

\begin{abstract}
Purpose of review Cancer vaccines are one of the most extensively studied immunotherapy type in solid tumors. Despite favorable presuppositions, so far, the use of cancer vaccines has been associated with disappointing results. However, a new generation of vaccines has been developed, promising to revolutionize the immunotherapy field.

Recent findings In this review, we aim to highlight the advances in cancer vaccines and the remaining hurdles to overcome. Summary Cancer vaccination has experienced tremendous progress in the last decade, with myriad promising developments. Future efforts should focus on optimization of target identification, streamlining of most appropriate vaccination strategies, and adjuvant development, as well as predictive biomarker identification. Cautious optimism is warranted in the face of early successes seen in recent clinical trials for oncolytic vaccines. If an approach were to prove successful, it could revolutionize cancer therapy the way ICIs did in the previous decade.
\end{abstract}

Keywords Vaccines $\cdot$ NSCLC $\cdot$ Lung cancer $\cdot$ Immunotherapy

\section{Introduction}

This article is part of the Topical Collection on Lung Cancer

Christian Rolfo

christian.rolfo@mssm.edu

1 Oncology Department, Undivert Hospital, Geneva, Switzerland

2 Clinique Générale Beaulieu, Geneva, Switzerland

3 Department of Medical Oncology, Amsterdam UMC, Vrije Universiteit Amsterdam, Cancer Center Amsterdam, Amsterdam, Netherlands

4 Cancer Pharmacology Lab, AIRC Start-Up Unit, Fondazione Pisana Per La Scienza, Pisa, Italy

5 Medical Oncology Unit, A.O. Papardo, Messina, Italy

6 Center for Thoracic Oncology The Tisch Cancer Institute Icahn School of Medicine at Mount Sinai, Mount Sinai Health System, One Gustave Levy Place, Box 1079, New York, NY 10029, USA

7 Thoracic Oncology Unit, Instituto Nacional de Cancerología (INCan), Mexico City, Mexico

8 Foundation for Clinical and Applied Cancer Research (FICMAC)/Clinical and Traslational Oncology Group, Clínica del Country/Molecular Oncology and Biology Systems Research Group (Fox-G), Universidad El Bosque, Bogotá, Colombia
Immunotherapy in oncology can be defined as the manipulation of the immune system to recognize and destroy cancer cells [1]. In this context, the application of cancer vaccines represents the logical evolution and extension of their use in infectious diseases. However, attempts to reproduce the same results registered in the latter have been rather disappointing. There are a few exceptions, which are the generation of prophylactic vaccines against hepatitis B virus (HBV) and human papillomavirus (HPV), which subsequently impact the incidence and mortality of liver and cervical cancer, respectively [2]. While these are hailed as successes, their oncologic efficacy is indirect, through the prevention of viral infections. The choice of the right target antigen is essential while designing a vaccine [3]. Tumor-associated antigens (TAAs) are self-antigens abnormally expressed by tumor cells. Since high-affinity T cells recognizing self-antigens are eliminated during development by our immune system's central and peripheral tolerance mechanisms, TAA-directed cancer vaccines face the challenge of activating any remaining low affinity T cells. Despite these challenges, the TAA vaccines are the most studied cancer vaccines thus far. On the other hand, tumor-specific antigens (TSAs) are often patient specific, coming from nonsynonymous mutations or 
genetic alterations, or even virally introduced genetic information in cancer cells. In this situation, the TSAs recognized by high-affinity $\mathrm{T}$ cells are less likely to be subject to central tolerance and induce autoimmunity [4].

Cancer vaccines can be categorized as cellular, viral vector, or molecular (peptide, DNA, or RNA) (Fig. 1) [3]. In this review, we aim to highlight the advances in cancer vaccines and the remaining hurdles to overcome.

\section{TAA Vaccines}

As mentioned above, most cancer vaccines have targeted TAAs, which include cancer/germline antigens normally expressed only in immune privileged germline cells such as MAGE-A1, MAGE-A3, and NY-ESO-1 [5-7], cell lineage differentiation antigens, normally not expressed in adult tissues, such as tyrosinase, gp100, and MART-1 (PSA and prostatic acid phosphatase (PAP)) [8-10], and antigens that are overexpressed in cancer cells such as hTERT, HER2, mesothelin, and MUC-1 [11-13].
Developing such vaccines presents several challenges. TAAs, as self-antigens, B cells, and T cells that strongly recognize these antigens may have been removed from the immune repertoire by central and peripheral tolerance. Given this problem, any cancer vaccine TAA should be able to break the tolerance through stimulation of the low affinity or even rare TAA-reactive T cells remaining [14]. A mechanism to stimulate and increase T cell affinity is the use of strong adjuvants, co-stimulators, and repeated vaccination [15]. Despite this, though, in many cases the immune responses registered have been low and the clinical benefit marginal.

The most relevant and reliable measure of $\mathrm{T}$ cell activation is the quantity and quality of tumor-infiltrating $\mathrm{T}$ cells (TILs). Such analyses have become common in cancer vaccine development. A further challenge is that targeting TAAs, even ones overexpressed by the cancer itself, might result in increased toxicity. On-target, off-tumor toxicity has been observed in clinical studies. Chimeric antigen receptor-engineered $\mathrm{T}$ cell therapy (CAR-T) targeting colorectal carcinoembryonic antigen (CEA) causes severe colitis in a

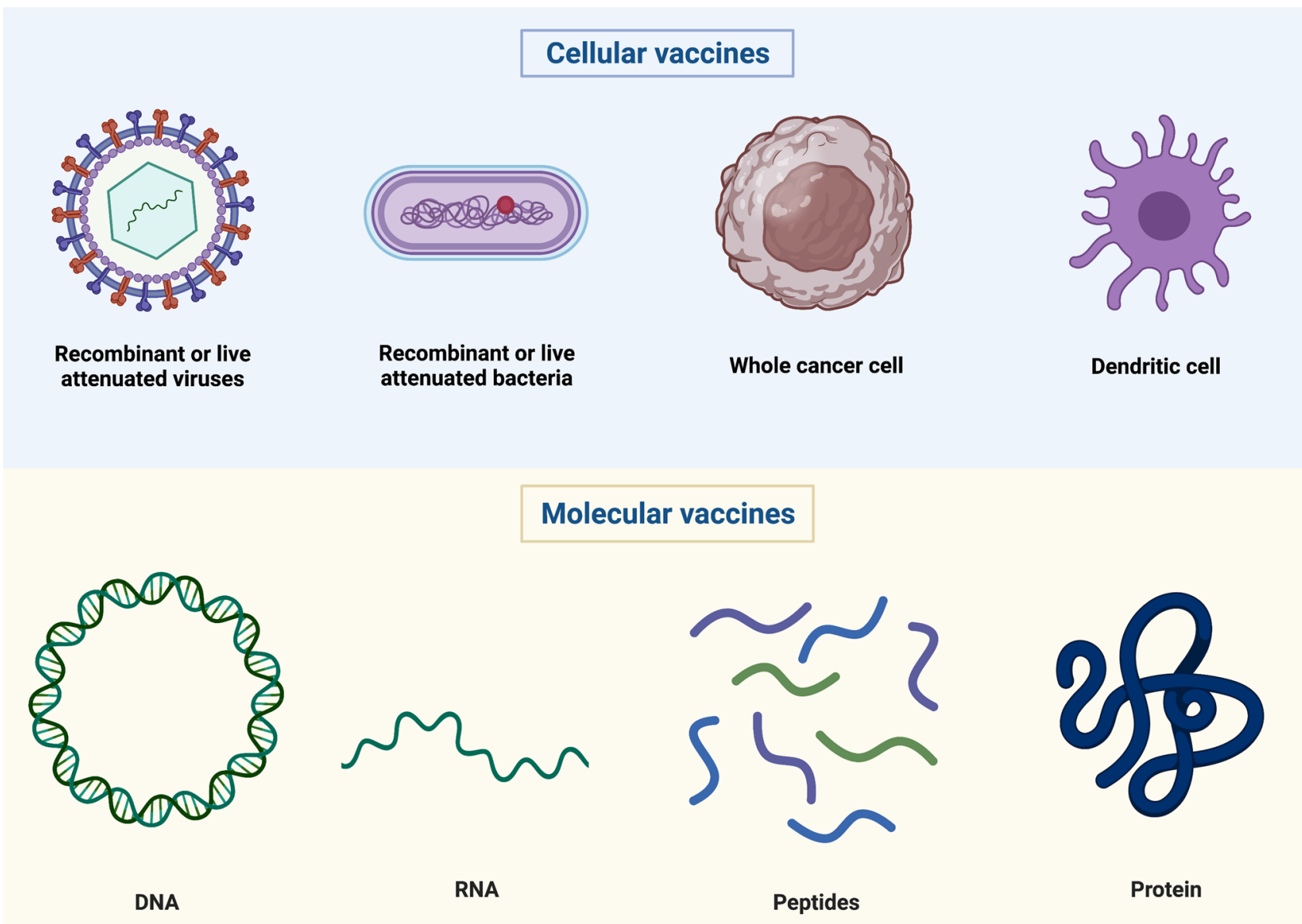

Fig. 1 Different categories of cancer vaccines on the basis of the vector used (Credit: created with BioRender.com) 
high percentage of patients, as this antigen is also expressed in normal intestinal tissue [16].

\section{Oncogenic Viral Antigens}

The potential impact and importance of developing cancerpreventing vaccines targeting viral antigens are quite simple to understand if we consider that approximately $10 \%$ of human cancers worldwide are caused by viral infections [17]. Those antigens are potentially highly immunogenic, and sometimes molecular drivers of oncogenesis. An example of a successful vaccine is the one comprising HBV surface antigens, highly effective in preventing infection and reducing the incidence of hepatocellular carcinoma (HCC). Similarly, a vaccine comprising HPV-like particles has provided protection against HPV infections and pre-cancerous lesions [18-21]. These vaccines are effective in preventing cancer, but have a main limitation: they lack or have only a very modest activity on established cancers. This is likely due to the fact that humoral immunity cannot efficiently eradicate large numbers of virus-infected cancer cells, which instead require cell-mediated immune responses. An alternative strategy, for instance in HPV-induced cancer, has been the development of distinct HPV vaccines targeting $\mathrm{T}$ cell epitopes of the viral E6 and E7 oncoproteins. These oncoproteins are expressed within infected cells and then processed and presented to stimulate cytotoxic T cells. Several different E6 and E7 vaccines are being tested in patients with cervical intraepithelial neoplasia (CIN), cervical cancer, and head and neck cancer [22-24] (Table 1).

For established cancer, in 2018, the FDA approved the first oncolytic virus for cancer treatment, talimogene laherparepvec (T-VEC) [25]. It relies on direct intratumoral injections to overcome dilution and neutralization in blood. It induces cell lysis and promotes antitumor immune responses locally and in distant lesions [26••, 27, 28•]. In a randomized phase II trial, T-VEC was combined with an antiCTLA4, ipilimumab, in first or second line, and the combination showed a significantly higher objective response rate (ORR) compared to ipilimumab alone in patients with metastatic melanoma [27]. In the same patient population, the phase III OPTiM study demonstrated improved progression-free survival (PFS), ORR, and overall survival (OS) of T-VEC alone compared to GM-CSF [28•].

It is essential to stress that data coming from relatively small phase II studies should be confirmed, whenever possible, in larger phase III trials. It is not rare for preclinical and clinical data on small patient samples not to be confirmed in larger studies. A good example is the PROSTVAC-VF/ Tricom vaccine that used recombinant poxviruses expressing prostate-specific antigen (PSA) for priming, followed by subsequent booster doses of a fowlpox virus encoding PSA.
The study showed OS benefit in prostate cancer [29], but a more recent phase III trial of PROSTVAC in castrationresistant prostate cancer was discontinued due to futility at interim analysis [30].

To disrupt the tumor microenvironment (TME), viruses have been engineered to express targeted antigens and immunomodulatory molecules. Examples are the vaccine TG4010 that contains the modified vaccinia virus (MVA)-expressing tumor antigen, MUC-1, the immunostimulatory cytokine, IL2 [31], the TroVax which is an MVA-expressing oncofetal antigen 5T4 (MVA-5T4) [32], and the MG1 that is a version of the oncolytic Maraba virus engineered with added transgene capacity for targeted expression of TAAs and immunomodulatory agents [33]. The latter has been assessed in non-small cell lung cancer and human papilloma virus (HPV)-associated tumors [34, 35]. Furthermore, the MEDI5395, an attenuated Newcastle disease virus (NDV) engineered to express GM-CSF, entered phase I clinical trials in 2019 and results are awaited in 2021. Lastly, the B cell/monocyte-based vaccine, BVAC-C, transfected with recombinant viruses, such as HPV 16/18 E6/E7, has shown some activity in activating virus-specific T cells in a phase I study of patients with recurrent cervical cancer. In the trial, 10 patients who had experienced recurrence after at least one prior platinum-based combination chemotherapy received three intravenous infusion of BVAC-C. It was well tolerated, and of the 8 patients evaluable, one partial response (12.5\%) and four stable diseases (50\%) were seen. Immunologic response analysis showed that BVAC-C induced activation of natural killer T cells, natural killer cells, and HPV E6/ E7 specific CD4 and CD8 T cells upon vaccinations in all patients evaluated. A phase II study is underway [36], as it is a phase I study of BVAC-B, transfected with recombinant $H E R 2 /$ neu, in patients with gastric cancer [37].

\section{Peptide-Based Vaccines}

Many peptide vaccine clinical trials have been conducted with demonstration of immune responses, yet significant clinical benefit has been elusive. Often, only single antigen-based short peptides are used. These may not be able to overcome antigen heterogeneity or loss of antigen expression within the tumor or stimulate robust immune responses $[38,39]$. In contrast to short peptides, the use of multivalent synthetic long peptides (SLPs), containing both MHC class I and class II epitopes, can elicit a balanced induction of both CD8 and CD4 T cells [40].

SLP immune-therapeutics have been developed. They consist of highly immunogenic long peptides engineered to avoid central tolerance mechanisms by efficiently delivering antigens to dendritic cells (DCs), inducing CD4 + and $\mathrm{CD} 8+\mathrm{T}$ cell responses [41]. Early clinical trials have 


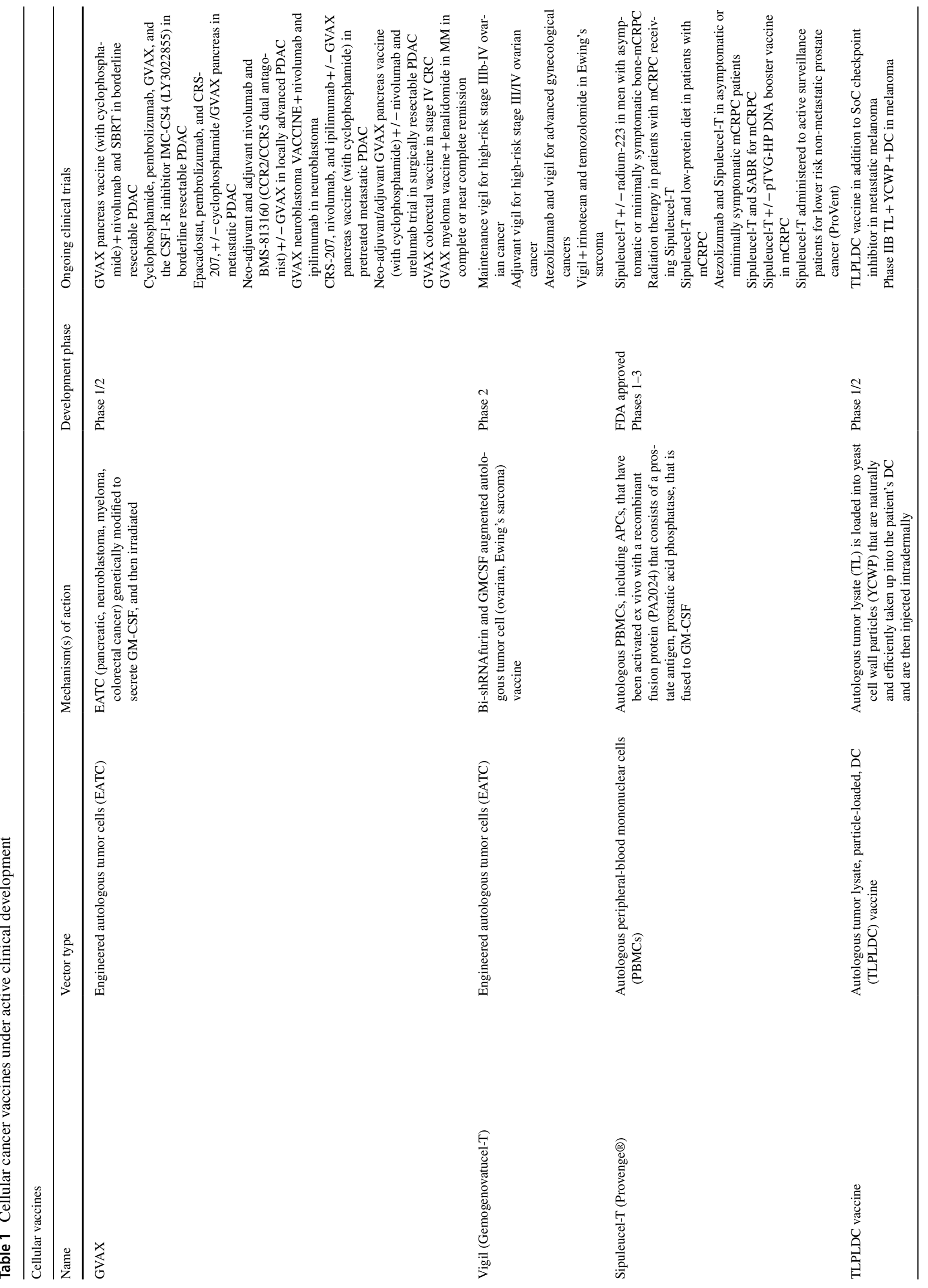




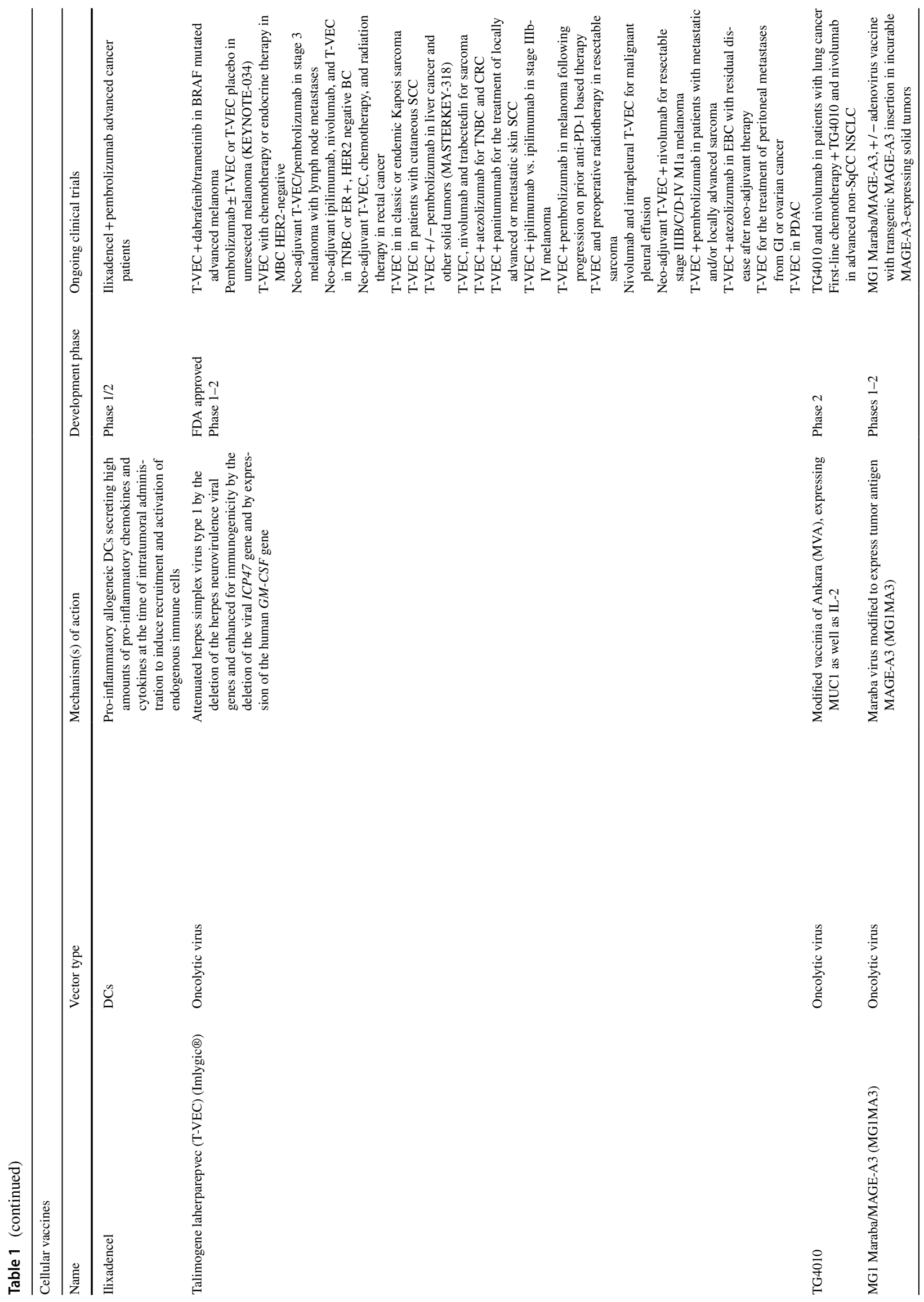




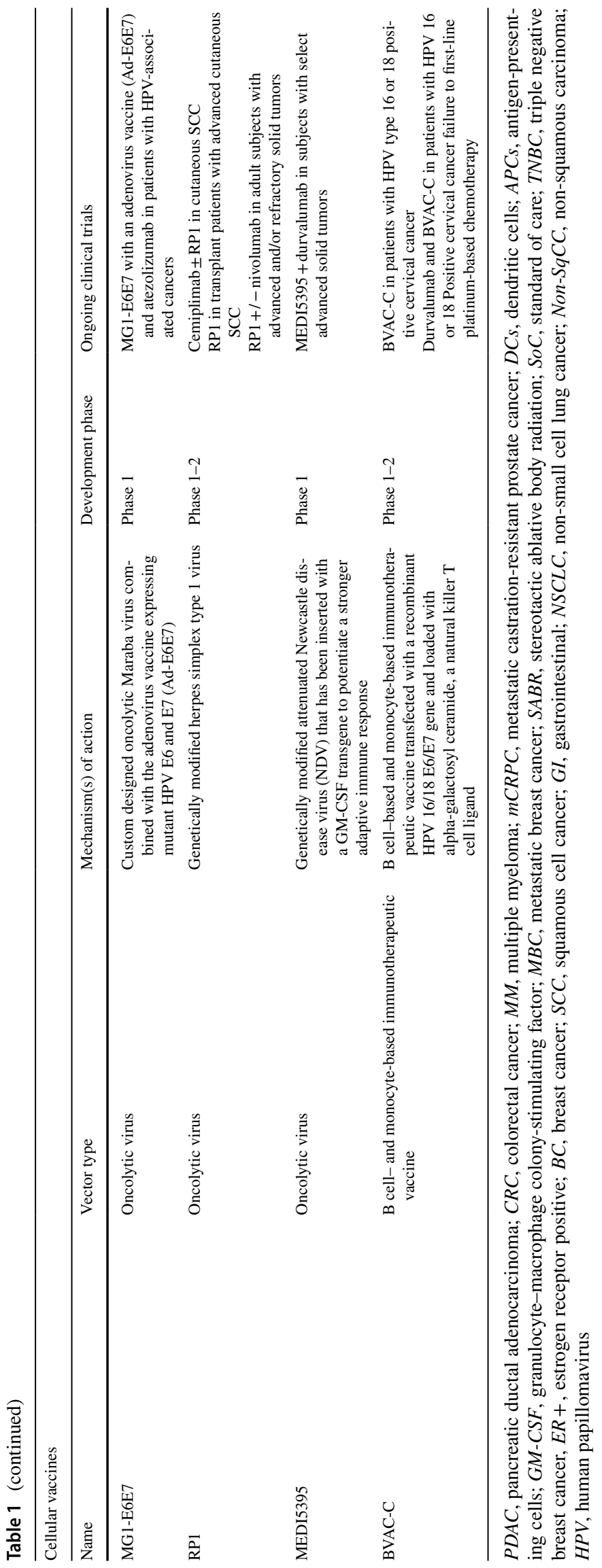


shown a good safety profile and promising activity. For instance, in a phase II trial, the SLP vaccine ISA101 combined with the anti-PD-1 immune checkpoint antibody nivolumab was well tolerated in 24 patients with HPV16-positive cancer. The efficacy appeared superior to that of nivolumab monotherapy [42•]. Furthermore, a phase I/II study of ISA101 combined with standard platinumbased chemotherapy in 77 patients with metastatic HPV16-positive cervical cancer showed a strong correlation between strong vaccine-induced HPV-16-specific T cell response and OS [43].

The SVN53-67/M57-KLH (SurVaxM) is another peptide-based vaccine consisting of an SLP mimic engineered to trigger an immune response by targeting survivin, which is highly expressed in many cancers $[44,45]$. The vaccine SurVaxM is under investigation in a phase I study in patients with survivin-positive neuroendocrine tumors (NCT03879694) [46].

A novel technology platform, T-win, was developed to allow identification, design, and validation of immune modulatory peptide-based vaccine candidates targeting the TME [47]. T-win vaccination has led to an antitumor response in vitro and vivo and synergizes with anti-PD-1 antibody treatment [48]. It is likely that $\mathrm{T}$-win vaccination may lead to the expansion of $\mathrm{T}$ cells counteracting and modulating the immune suppressive environment within the TME.

The major T-win technology challenge is to activate the most potent anti-Treg immune response, while minimizing autoimmunity and subsequent toxicity.

\section{DNA Vaccines}

Similar to peptide vaccines, DNA and RNA vaccines have the advantage of relatively simple and inexpensive production. They can also trip nucleic acid sensors that activate DCs, including certain TLRs, STING, AIM2, and DAI pathways; hence, adjuvant co-stimulators are often less important.

DNA vaccination holds great promise in cancer. They use plasmids to ensure the delivery of tumor antigen-encoding genes. DNA vaccines allow the encoded antigen to be presented by MHC classes I and II, with subsequent activation of both CD4 and CD8 T cells and, indirectly, humoral immunity [49]. Furthermore, the intrinsic elements of plasmid DNA can also activate the innate immune response due to the recognition of the double-stranded DNA structure by cytosolic sensors [50]. Despite encouraging preclinical data and the improvement in the delivery techniques, DNA vaccines have not revealed high immunogenicity in human trials so far [51].

\section{RNA Vaccines}

RNA cancer vaccines offer advantages over DNA vaccines. In fact, RNA is more susceptible to degradation by ubiquitous RNases and this could be undermined by chemical modifications and incorporation of modified nucleosides such as pseudouridine [52, 53]. RNA, unlike DNA, cannot be integrated into the genome; therefore, it has no oncogenic potential. Furthermore, RNA only needs to enter the cytoplasm, whereas DNA needs to enter the nucleus, thus facing an additional barrier, the nuclear membrane. Many mRNA vaccine platforms have been developed recently and validated [54-56]. The possibility of engineering the RNA sequence has made synthetic mRNA more manageable than before. Furthermore, efficient and non-toxic RNA carriers have been developed that allow prolonged antigen expression in vivo [57].

RNA vaccines have traditionally been based on mRNA in trials to date. This approach is being challenged by the use of RNA replicons [58]. As the latter are self-replicating, they are thought to be longer lasting than mRNA vaccines and may require fewer vaccinations to elicit the desired response. Transfection efficiency and the duration of RNA replicons before degradation could be further improved with novel vaccine delivery approaches. Two possibilities consist of condensing RNA with protamine and encapsulating it into liposomal particles.

Recently, a phase I trial in metastatic melanoma patients assessed mRNA expressing a variety of TAAs grouped together in a liposome [59]. The antigens triggered $\mathrm{T}$ cell responses which were accompanied by disease control or tumor response.

\section{Conclusion and Future Perspectives}

Cancer immunotherapy has experienced tremendous progress in the last decade, with improvement of our understanding of cancer biology and immune escape mechanisms. It is therefore an exciting time in the field of immune therapies, including cancer vaccines, with myriad promising developments.

Considering the increasing number of approved monoclonal antibodies for cancer treatment, the development of antibody inducing vaccines represents an important opportunity to improve the armamentarium of therapeutic strategies against many tumor types. Of note, the effectivity of a polyclonal antibody response is expected to exceed the one of monoclonal antibodies, as reported in both preclinical studies that demonstrate pronounced antitumor responses 
and in early clinical trials showing benefit in patients with advanced cancer [60].

Furthermore, the exponential expansion over the past decade in the ability to sequence the genetic profile of an individual cancer patient has opened the door to a deeper understanding of cancer's underlying biology through the checkpoint blockade therapy response, as well as to finding better antigens to target, though computational assessment of the mutations that have the most potential in stimulating the immune response of each patient.

With the concept of personalized cancer therapy and immunotherapy, panels of genomic and proteomic biomarkers predictive for response following molecular profiling of tumor and host cells using next-generation sequencing are expected to further help to shape the treatment and improve outcomes for patients with cancer. Moreover, vaccination strategies are expected to reduce hospital visits, resulting in enhanced quality of life, and most of these strategies are extremely cost-effective, keeping affordable costs for anticancer treatments, and offering socio-economic benefits, especially when compared to the prohibitively high drug costs of most recently developed anticancer agents.

As a future perspective, it is likely that some cancer vaccines could become the next preferred combination partner for long-term cancer treatments, serving as a platform that is easily combinable with existing therapies, such as immune checkpoint inhibitors, which have already dramatically risen therapeutic expectations in numerous cancers. This would provide innovative treatment options in which either combination therapy can be given as multi-target vaccines or vaccination is combined with conventional therapy or immunotherapy.

There are still hurdles to overcome in order to maximize success.

Future efforts should focus on optimization of target identification, streamlining of most appropriate vaccination strategies, and adjuvant development.

Another major concern is the current lack of validated biomarkers predictive of vaccine efficacy. The concept that vaccine-induced TILs increase is a plausible possibility, but the quantity and quality of TILs required for clinical efficacy are still unknown and probably vary for different vaccines and cancer settings. Furthermore, understanding which subtypes of $\mathrm{T}$ cells are more relevant for an effective cancer vaccine, and how to more selectively stimulate them, remains a little-understood challenge.

New strategies to improve outcomes are essential. These may include combinations of cancer vaccines with agents that increase MHC expression. Each novel approach will be accompanied by potential toxicities and unexpected challenges. Cautious optimism is warranted in the face of early successes seen in recent clinical trials for oncolytic vaccines. If an approach were to prove successful, it could revolutionize cancer therapy this decade the way checkpoint inhibition did in the previous decade.

\section{Declarations}

Conflict of Interest Dr. Friedlander reports personal fees from Bristol-Myers Squibb, Roche, Pfizer, Merck Sharp and Dohme, and Astellas outside the submitted work; Dr. Addeo reports personal fees from Bristol-Myers Squibb, AstraZeneca, Roche, Pfizer, Merck Sharp and Dohme, and Boehringer-Ingelheim; Dr. Russo reports personal fees for attending advisory board meetings from Astra Zeneca, MSD, and Novartis outside the submitted work. Dr. Arrieta reports personal fees from Pfizer, grants and personal fees from AstraZeneca, grants, personal fees from Boehringer-Ingelheim, personal fees from Lilly, personal fees from Merck, personal fees from Bristol-Myers Squibb, and grants and personal fees from Roche, outside the submitted work; Dr. Cardona discloses financial research support from Merck Sharp \& Dohme, Boehringer-Ingelheim, Roche, Bristol-Myers Squibb, Foundation Medicine, Roche Diagnostics, Thermo Fisher, Broad Institute, BioNTech, Amgen, Flatiron Health, Teva Pharma, Rochem Biocare, Bayer, INQBox, and The Foundation for Clinical and Applied Cancer Research - FICMAC. Additionally, he was linked and received honoraria as advisor, participated in speakers' bureau, and gave expert testimony to EISAI, Merck Serono, Janssen Pharmaceutical, Merck Sharp \& Dohme, Boehringer-Ingelheim, Roche, Bristol-Myers Squibb, Pfizer, Novartis, Celldex Therapeutics, Foundation Medicine, Eli Lilly, Guardant Health, Illumina, and Foundation for Clinical and Applied Cancer Research - FICMAC; Dr. Rolfo reports grants for Lung Cancer Research Foundation-Pfizer Grant 2019 NHI U54 grant (Project co-leader). He has received personal fees for attending advisory board with Inivata, ArcherDx, MD Serono, BMS, Novartis, and Boston Pharmaceuticals; fee for speaking bureau: MSD, Astra Zeneca, Roche. Non-financial conflict included research collaboration: Guardant Health. The other authors have non-financial relationship to disclose.

\section{References}

Papers of particular interest, published recently, have been highlighted as:

- Of importance

$\bullet$ Of major importance

1. Russo A, McCusker MG, Scilla KA, Arensmeyer KE, Mehra $\mathrm{R}$, Adamo V, et al. Immunotherapy in lung cancer: from a minor God to the Olympus. Adv Exp Med Biol United States. 2020;1244:69-92.

2. Kim BK, Han K-H, Ahn SH. Prevention of hepatocellular carcinoma in patients with chronic hepatitis B virus infection. Oncology. Switzerland; 2011;81 Suppl 1:41-9.

3. Hollingsworth RE, Jansen K. Turning the corner on therapeutic cancer vaccines. NPJ Vaccines. 2019;4:7.

4. Osipov A, Murphy A, Zheng L. From immune checkpoints to vaccines: the past, present and future of cancer immunotherapy. Adv Cancer Res United States. 2019;143:63-144.

5. Gnjatic S, Ritter E, Büchler MW, Giese NA, Brors B, Frei C, et al. Seromic profiling of ovarian and pancreatic cancer. Proc Natl Acad Sci U S A. 2010;107:5088-93. 
6. Hofmann O, Caballero OL, Stevenson BJ, Chen Y-T, Cohen $\mathrm{T}$, Chua R, et al. Genome-wide analysis of cancer/testis gene expression. Proc Natl Acad Sci U S A. 2008;105:20422-7.

7. Simpson AJG, Caballero OL, Jungbluth A, Chen Y-T, Old LJ. Cancer/testis antigens, gametogenesis and cancer. Nat Rev Cancer England. 2005;5:615-25.

8. Kawakami Y, Eliyahu S, Delgado CH, Robbins PF, Sakaguchi K, Appella E, et al. Identification of a human melanoma antigen recognized by tumor-infiltrating lymphocytes associated with in vivo tumor rejection. Proc Natl Acad Sci U S A. 1994;91:6458-62.

9. Parkhurst MR, Fitzgerald EB, Southwood S, Sette A, Rosenberg SA, Kawakami Y. Identification of a shared HLAA*0201-restricted T-cell epitope from the melanoma antigen tyrosinase-related protein 2 (TRP2). Cancer Res United States. 1998;58:4895-901.

10. Correale P, Walmsley K, Nieroda C, Zaremba S, Zhu M, Schlom $\mathrm{J}$, et al. In vitro generation of human cytotoxic T lymphocytes specific for peptides derived from prostate-specific antigen. $\mathbf{J}$ Natl Cancer Inst United States. 1997;89:293-300.

11. Disis ML, Wallace DR, Gooley TA, Dang Y, Slota M, Lu H, et al. Concurrent trastuzumab and HER2/neu-specific vaccination in patients with metastatic breast cancer. J Clin Oncol. 2009;27:4685-92.

12. Chang K, Pastan I. Molecular cloning of mesothelin, a differentiation antigen present on mesothelium, mesotheliomas, and ovarian cancers. Proc Natl Acad Sci U S A. 1996;93:136-40.

13. Finn OJ, Gantt KR, Lepisto AJ, Pejawar-Gaddy S, Xue J, Beatty PL. Importance of MUC1 and spontaneous mouse tumor models for understanding the immunobiology of human adenocarcinomas. Immunol Res United States. 2011;50:261-8.

14. Pedersen SR, Sørensen MR, Buus S, Christensen JP, Thomsen AR. Comparison of vaccine-induced effector CD8 T cell responses directed against self- and non-self-tumor antigens: implications for cancer immunotherapy. J Immunol United States. 2013;191:3955-67.

15. Overwijk WW. Cancer vaccines in the era of checkpoint blockade: the magic is in the adjuvant. Curr Opin Immunol England. 2017;47:103-9.

16. Parkhurst MR, Yang JC, Langan RC, Dudley ME, Nathan D-AN, Feldman SA, et al. T cells targeting carcinoembryonic antigen can mediate regression of metastatic colorectal cancer but induce severe transient colitis. Mol Ther. 2011;19:620-6.

17. de Martel C, Ferlay J, Franceschi S, Vignat J, Bray F, Forman $\mathrm{D}$, et al. Global burden of cancers attributable to infections in 2008: a review and synthetic analysis. Lancet Oncol England. 2012;13:607-15.

18. de Vos van Steenwijk PJ, van Poelgeest MIE, Ramwadhdoebe TH, Löwik MJG, Berends-van der Meer DMA, van der Minne $\mathrm{CE}$, et al. The long-term immune response after HPV16 peptide vaccination in women with low-grade pre-malignant disorders of the uterine cervix: a placebo-controlled phase II study. Cancer Immunol Immunother. Germany; 2014;63:147-60.

19. Ault KA. Effect of prophylactic human papillomavirus L1 viruslike-particle vaccine on risk of cervical intraepithelial neoplasia grade 2, grade 3, and adenocarcinoma in situ: a combined analysis of four randomised clinical trials. Lancet England. 2007;369:1861-8.

20. Wang JW, Hung C-F, Huh WK, Trimble CL, Roden RBS. Immunoprevention of human papillomavirus-associated malignancies. Cancer Prev Res (Phila). 2015;8:95-104.

21. Schiller JT, Lowy DR. Understanding and learning from the success of prophylactic human papillomavirus vaccines. Nat Rev Microbiol. 2012;10:681-92.

22. Trimble CL, Morrow MP, Kraynyak KA, Shen X, Dallas M, Yan J, et al. Safety, efficacy, and immunogenicity of VGX-3100, a therapeutic synthetic DNA vaccine targeting human papillomavirus 16 and 18 E6 and E7 proteins for cervical intraepithelial neoplasia 2/3: a randomised, double-blind, placebo-controlled phase $2 b$ trial. Lancet. 2015;386:2078-88.

23. Alvarez RD, Huh WK, Bae S, Lamb LSJ, Conner MG, Boyer J, et al. A pilot study of pNGVL4a-CRT/E7(detox) for the treatment of patients with HPV16+ cervical intraepithelial neoplasia 2/3 (CIN2/3). Gynecol Oncol. 2016;140:245-52.

24. Kim TJ, Jin H-T, Hur S-Y, Yang HG, Seo YB, Hong SR, et al. Clearance of persistent HPV infection and cervical lesion by therapeutic DNA vaccine in CIN3 patients. Nat Commun. 2014;5:5317.

25. Conry RM, Westbrook B, McKee S, Norwood TG. Talimogene laherparepvec: first in class oncolytic virotherapy. Hum Vaccin Immunother. 2018;14:839-46.

26.• Andtbacka RHI, Kaufman HL, Collichio F, Amatruda T, Senzer $\mathrm{N}$, Chesney J, et al. Talimogene laherparepvec improves durable response rate in patients with advanced melanoma. J Clin Oncol United States. 2015;33:2780-8. First phase III clinical trial demonstrating that an oncolytic vaccine (T-VEC) is associated with therapeutic benefit against melanoma in a phase III clinical trial.

27. Chesney J, Puzanov I, Collichio F, Singh P, Milhem MM, Glaspy J, et al. Randomized, open-label phase II study evaluating the efficacy and safety of talimogene laherparepvec in combination with ipilimumab versus ipilimumab alone in patients with advanced, unresectable melanoma. J Clin Oncol. 2018;36:1658-67.

28. Andtbacka RHI, Collichio F, Harrington KJ, Middleton MR, Downey G, Öhrling K, Kaufman HL. Final analyses of OPTiM: a randomized phase III trial of talimogene laherparepvec versus granulocyte-macrophage colony-stimulating factor in unresectable stage III-IV melanoma. J Immunother Cancer. 2019.Final results of the OPTiM study, confirming the long-term benefit of T-VEC in melanoma patients.

29. Kantoff PW, Gulley JL, Pico-Navarro C. Revised overall survival analysis of a phase II, randomized, double-blind, controlled study of PROSTVAC in men with metastatic castration-resistant prostate cancer. J Clin Oncol. 2017;35:124-5.

30. Gulley JL, Borre M, Vogelzang NJ, Ng S, Agarwal N, Parker $\mathrm{CC}$, et al. Phase III trial of PROSTVAC in asymptomatic or minimally symptomatic metastatic castration-resistant prostate cancer. J Clin Oncol. 2019;37:1051-61.

31. Oudard S, Rixe O, Beuselinck B, Linassier C, Banu E, Machiels J-P, et al. A phase II study of the cancer vaccine TG4010 alone and in combination with cytokines in patients with metastatic renal clear-cell carcinoma: clinical and immunological findings. Cancer Immunol Immunother Germany. 2011;60:261-71.

32. Amato RJ, Hawkins RE, Kaufman HL, Thompson JA, Tomczak P, Szczylik C, et al. Vaccination of metastatic renal cancer patients with MVA-5T4: a randomized, double-blind, placebocontrolled phase III study. Clin Cancer Res United States. 2010;16:5539-47.

33. Pol JG, Zhang L, Bridle BW, Stephenson KB, Rességuier J, Hanson $\mathrm{S}$, et al. Maraba virus as a potent oncolytic vaccine vector. Mol Ther. 2014;22:420-9.

34. Pol JG, Acuna SA, Yadollahi B, Tang N, Stephenson KB, Atherton MJ, et al. Preclinical evaluation of a MAGE-A3 vaccination utilizing the oncolytic Maraba virus currently in first-in-human trials. Oncoimmunology. 2019;8:e1512329.

35. Atherton MJ, Stephenson KB, Pol J, Wang F, Lefebvre C, Stojdl DF, et al. Customized viral immunotherapy for HPV-associated cancer. Cancer Immunol Res United States. 2017;5:847-59.

36. Choi CH, Choi HJ, Lee J-W, Kang E-S, Cho D, Park BK, et al. Phase I study of a B cell-based and monocyte-based 
immunotherapeutic vaccine, BVAC-C in human papillomavirus type 16- or 18-positive recurrent cervical cancer. J Clin Med. 2020;9.

37. Lee JB, Kwon WS, Kim HS, Jung M, Kim S, Park M, et al. First-in-human phase I study of BVAC-B cell therapy in HER2-positive advanced gastric cancer. JCO Wolters Kluwer. 2020;38:4534-4534.

38. Cecco S, Muraro E, Giacomin E, Martorelli D, Lazzarini R, Baldo P, et al. Cancer vaccines in phase II/III clinical trials: state of the art and future perspectives. Curr Cancer Drug Targets Netherlands. 2011;11:85-102.

39. Lesterhuis WJ, Haanen JBAG, Punt CJA. Cancer immunotherapy-revisited. Nat Rev Drug Discov England. 2011;10:591-600.

40. Zhang H, Hong H, Li D, Ma S, Di Y, Stoten A, et al. Comparing pooled peptides with intact protein for accessing cross-presentation pathways for protective CD8+ and CD4+ T cells. J Biol Chem. 2009;284:9184-91.

41. Melief CJM, van Hall T, Arens R, Ossendorp F, van der Burg SH. Therapeutic cancer vaccines. J Clin Invest. 2015;125:3401-12.

42. Massarelli E, William W, Johnson F, Kies M, Ferrarotto R, Guo $\mathrm{M}$, et al. Combining immune checkpoint blockade and tumorspecific vaccine for patients with incurable human papillomavirus 16-related cancer: a phase 2 clinical trial. JAMA Oncol. 2019;5:67-73. Promising results of a phase II study combining a PD-1 inhibitor with ISA 101, a synthetic long-peptide HPV-16 vaccine, in patients with incurable HPV-16-positive cancer.

43. Melief CJM, Welters MJP, Vergote I, Kroep JR, Kenter GG, Ottevanger PB, et al. Strong vaccine responses during chemotherapy are associated with prolonged cancer survival. Sci Transl Med. United States; 2020;12.

44. Fenstermaker RA, Ciesielski MJ, Qiu J, Yang N, Frank CL, Lee KP, et al. Clinical study of a survivin long peptide vaccine (SurVaxM) in patients with recurrent malignant glioma. Cancer Immunol Immunother. 2016;65:1339-52.

45. Fenstermaker RA, Figel SA, Qiu J, Barone TA, Dharma SS, Winograd EK, et al. Survivin monoclonal antibodies detect survivin cell surface expression and inhibit tumor growth in vivo. Clin Cancer Res. 2018;24:2642-52.

46. Hanif A, Lee S, Gupta M, Chander A, Kannisto ED, Punnanitinont A, et al. Exploring the role of survivin in neuroendocrine neoplasms. Oncotarget. 2020;11:2246-58.

47. Andersen $\mathrm{MH}$. The T-win ${ }^{\circledR}$ technology: immune-modulating vaccines. Semin Immunopathol Germany. 2019;41:87-95.

48. Dey S, Sutanto-Ward E, Kopp KL, DuHadaway J, Mondal A, Ghaban D, et al. Peptide vaccination directed against IDO1expressing immune cells elicits CD8(+) and CD4(+) T-cellmediated antitumor immunity and enhanced anti-PD1 responses. J Immunother Cancer. 2020;8.
49. Li L, Petrovsky N. Molecular mechanisms for enhanced DNA vaccine immunogenicity. Expert Rev Vaccines. 2016;15:313-29.

50. Ori D, Murase M, Kawai T. Cytosolic nucleic acid sensors and innate immune regulation. Int Rev Immunol England. 2017;36:74-88.

51. Suschak JJ, Williams JA, Schmaljohn CS. Advancements in DNA vaccine vectors, non-mechanical delivery methods, and molecular adjuvants to increase immunogenicity. Hum Vaccin Immunother. 2017;13:2837-48.

52. Karikó K, Weissman D. Naturally occurring nucleoside modifications suppress the immunostimulatory activity of RNA: implication for therapeutic RNA development. Curr Opin Drug Discov Devel England. 2007;10:523-32.

53. Karikó K, Muramatsu H, Welsh FA, Ludwig J, Kato H, Akira S, et al. Incorporation of pseudouridine into mRNA yields superior nonimmunogenic vector with increased translational capacity and biological stability. Mol Ther. 2008;16:1833-40.

54. Petsch B, Schnee M, Vogel AB, Lange E, Hoffmann B, Voss D, et al. Protective efficacy of in vitro synthesized, specific mRNA vaccines against influenza A virus infection. Nat Biotechnol United States. 2012;30:1210-6.

55. Geall AJ, Verma A, Otten GR, Shaw CA, Hekele A, Banerjee K, et al. Nonviral delivery of self-amplifying RNA vaccines. Proc Natl Acad Sci U S A. 2012;109:14604-9.

56. Pardi N, Hogan MJ, Pelc RS, Muramatsu H, Andersen H, DeMaso CR, et al. Zika virus protection by a single lowdose nucleoside-modified mRNA vaccination. Nature. 2017;543:248-51.

57. Pardi N, Tuyishime S, Muramatsu H, Kariko K, Mui BL, Tam YK, et al. Expression kinetics of nucleoside-modified mRNA delivered in lipid nanoparticles to mice by various routes. J Control Release. 2015;217:345-51.

58. Lundstrom K. Replicon RNA viral vectors as vaccines. Vaccines (Basel). 2016;4.

59. Kranz LM, Diken M, Haas H, Kreiter S, Loquai C, Reuter $\mathrm{KC}$, et al. Systemic RNA delivery to dendritic cells exploits antiviral defence for cancer immunotherapy. Nature England. 2016;534:396-401.

60. Gavilondo JV, Hernández-Bernal F, Ayala-Ávila M, de la Torre AV, de la Torre J, Morera-Díaz Y, et al. Specific active immunotherapy with a VEGF vaccine in patients with advanced solid tumors. Results of the CENTAURO antigen dose escalation phase I clinical trial. Vaccine. Netherlands; 2014;32:2241-50.

Publisher's Note Springer Nature remains neutral with regard to jurisdictional claims in published maps and institutional affiliations. 